ESPINOSA: UM PENSAMENTO DA ATUALIDADE E DA CRÍTICA À UTOPIA POLÍTICA

Daniel Santos da Silva.

INSTRUÇÕES PARA OS AUTORES

\section{A SECULARIZAÇÃO DOS AFETOS RELIGIOSOS NOS ESCRITOS DE SPINOZA: ESPERANÇA E MEDO, AMOR E \\ GENEROSIDADE}

Gábor Boros*

Resumo: Posicionando-se como "filósofo natural" no tratamento das paixões, Descartes dá início a uma secularização dos afetos ou emoções. Nisso ele é seguido por Spinoza. Em ambos os casos a abordagem filosófica dos afetos tem como consequência desvinculá-los da perspectiva moral, secularizando as emoções: separadas da moral, sua explicação desvincula-se ao mesmo tempo da religião, já que a moral encontra seus fundamentos no deus transcendente. Nesse ponto, Spinoza vai mais longe que Descartes, na secularização das emoções, pois nele o deus é naturalizado, Deus sive natura. A generosidade, por exemplo, não depende mais de um deus dotado de boa vontade, mas sim do exercício natural do homem dotado de razão como parte da Natureza racionalizada. De modo que nem mesmo o amor intelectual de Deus seria substituto do impulso moral religioso: em Spinoza, tal amor, assim como a generosidade e a amizade, inscrevem-se na ordem necessária da natureza, não dependendo de uma vontade livre divina, mas também não se reduzindo a uma vontade humana.

Palavras-chave: emoções, moral, secularização, amor, generosidade

Admitir a inequívoca tendência, na filosofia atual, de que as teorias das paixões e dos afetos, propostas por Descartes e Spinoza, experimentam uma renovação surpreendente, parece promissor para investigar o que a negação da ordem moral em Spinoza significa, no nível da teoria da emoção. Parece óbvio que uma das contribuições principais dos afetos para a vida moral do homem é conectar a esfera dos usos cotidianos com a esfera dos valores morais. O que podemos esperar e o que devemos temer, o que nos

* Professor Associado da Universidade Eötvös, Budapeste, Hungria.

Tradução de Maria Cristina dos Santos de Souza, Doutora pela UERJ; revista por Pablo Azevedo,

mestrando da UFRJ. 
é permitido ou urgente amar, e se, quando pensamos, nos encontramos no estado de felicidade, a resposta para todas estas questões depende claramente do que consideramos serem os valores morais básicos e como - se em todo caso - consideramos que eles estão ancorados em alguma espécie de realidade imutável e eterna, explorada tradicionalmente pelos administradores do folclore religioso. Por conseqüência, se alguém renega a consideração moralmente avaliativa das emoções, ele deve, também, renunciar, pelo menos temporariamente, a sua interpretação teológicoreligiosa e vice-versa: despojando estas emoções, tradicionalmente associadas a normas religiosas ou teológicas, precisamente desta base teológico-religiosa, estabelecendo uma exclusiva ligação entre estes afetos e nosso saeculum mundano, quer dizer, renunciando a uma importante parte da ordem moral. Assim, quando Descartes adverte o leitor de $A s$ paixões da alma de que sua "intenção era de explicar as paixões apenas como um filósofo natural, e não como um retórico ou mesmo como um filósofo moral", ele coloca a relação entre os afetos e os valores morais entre parênteses. E quando Spinoza repete esta exposição programática de Descartes no Prefácio da parte 3 da Ética - "Tratarei, assim, da natureza e da virtude dos afetos, bem como da potência da mente sobre eles, por meio do mesmo método pelo qual tratei, nas partes anteriores, de Deus e da Mente. E considerarei as ações e os apetites humanos exatamente como se fossem uma questão de linhas, de superfícies ou de corpos." (Spinoza 10, p.163)-, o que faz não é apenas seguir a linha cartesiana da "secularização" das emoções, mas dá um passo além: redefine teologia e religião em termos de sua própria nova moralidade, e assim, quando, mais tarde, restabelece a ligação entre esta religião e, pelo menos, alguns dos afetos, isto será equivalente à negação dos afetos religiosos morais.

Certamente, o significado de religião, de religiosidade, neste período, é um problema altamente controverso. Enquanto, para Descartes, parece óbvio que o catolicismo pós-reforma, filosoficamente arraigado no nominalismo medieval tardio, representa um papel enorme em sua filosofia (incluindo a ética), por outro lado, Spinoza é o pensador cujas idéias a respeito dos afetos (quase) religiosos são extremamente importantes, precisamente porque suas visões a respeito de religião são as mais controversas entre os filósofos modernos prematuramente proeminentes. De forma assumidamente arbitrária, escolhi esperança e medo, amor e generosidade como os afetos a serem investigados no contexto da ética, do conceito de religião e da política teológica de Spinoza. Após terminar a análise, espero ser capaz não apenas de colocar a questão concernente ao caráter preciso da negação da ordem moral em Spinoza, na forma da "secularização" das escolhidas emoções, mas também oferecer algumas tentativas de resposta para esta questão. Ao final, compararei a linha do argumento de Spinoza a algumas daquelas que encontramos nos textos de Tomás de Aquino.

\section{Esperança e Medo}

Hoje, teóricos da emoção são ambíguos sobre o caráter da esperança enquanto emoção - às vezes, ela é considerada como uma "emoção intelectual" - e, além disso, se perguntam esperança e medo podem ser tomados como um par simétrico, tal como amor e ódio. Nessa ocasião, escolhi este par de emoções, precisamente por que a esperança é, para Spinoza, não apenas um entre muitos outros afetos - afeto é o termo dele, o qual poderíamos chamar, hoje, emoção - porém, também, um entre os mais proeminentes. O tratamento dos afetos em sua Ética é geométrico no caráter. O que significa que, até certo ponto, isto ganha importância quando exatamente um afeto particular torna-se primeiramente mencionado e 
definido. A escala da esperança é absolutamente alta neste sentido: Spinoza introduz primeiramente os três afetos primários, desejo, alegria e tristeza. A segunda escala é conferida ao amor e ao ódio, porém, a terceira é atribuída à esperança - e ao temor. O que J. R. Averrill estabeleceu em um dos manuais contemporâneos, The Emotions, poderia ter sido uma afirmação de Spinoza: “A pessoa não pode esperar por alguma coisa a não ser que ele ou ela também tema que o evento esperado possa não acontecer. Esperança e temor são dois lados da mesma moeda, por assim dizer; por esta razão, o que concerne a um concerne também ao outro" (Averill 2, p.36-37). Para Spinoza, alegria e tristeza são, por assim dizer, os dois principais gêneros de afeto: todo afeto precisa pertencer a um deles. É quase evidente que a esperança é o afeto que pertence à alegria, ao passo que o temor é um afeto de tristeza. Porém, para contar a história inteira, temos de acrescentar que Spinoza é um dos cognitivistas principais entre os teóricos antigos da emoção. Para ele, os afetos são idéias e pressupõem idéias que constituem seus objetos intencionais. Ao analisar um afeto é extremamente importante, não apenas encontrar o gênero certo para ele, mas também conhecer em quais espécies de conhecimento a idéia tem sua origem. No que concerne à esperança e ao temor, suas definições respectivas deixam claro que o objeto esperado ou temido é representado em uma idéia da imaginação, termo usado por Spinoza para designar o mais baixo gênero de conhecimento. Temos uma idéia temporalmente certa de um evento futuro ou passado como o objeto intencional da esperança e do temor. Mas passado, presente e futuro não são nada mais do que características, não da coisa mesma, mas de nosso ser próprio, que é-afetado ou que foi-afetado; enquanto que as idéias que se originam na razão não têm relação com o tempo, com nossa afetação. Por conseqüência, partindo-se do fato de que as idéias básicas de esperança e de temor são inadequadas, segue-se que não é permitido, àquelas que são comandadas pela razão, terem estes dois afetos.
Os afetos da esperança e do medo não podem ser, por si mesmos, bons. [...] Assim, quanto mais nos esforçamos por viver sob a condução da razão, tanto mais nos esforçamos por depender menos da esperança e por nos livrar do medo; por dominar, o quanto pudermos, o acaso; e por dirigir nossas ações de acordo com o conselho seguro da razão. (Spinoza 10, IV, prop.47 e esc., p.321)

O homem inteiramente comandado pela razão é essencialmente sem-esperança. Contudo, se devemos admitir que o homem comandado pela razão não pode sempre 'conquistar a fortuna', isso é ainda mais válido no caso do homem comandado pela imaginação, mesmo que este já tenha percebido o caráter ilusório da maior parte de suas idéias inadequadas, especialmente no que concerne os eventos futuros que a imaginação considera como bons ou maus. Estas são precisamente as idéias das quais dependem suas esperanças e seus temores. Em uma passagem famosa de seu Tractatus de Intellectus Emendatione (§7), Spinoza compara o homem comandado pela imaginação, o qual detecta o caráter ilusório de seu mundo cotidiano, mas já não poderia encontrar o novo mundo da razão para alguém "que sofre de uma doença fatal": ele tem de "empregar um remédio, $[. .$.$] não obstante incerto, com toda a sua força. Apesar de$ tudo, sua esperança repousa nisto". Aqui novamente: o temor da morte necessariamente envolve a esperança de uma nova vida. Há, contudo, uma clara assimetria entre o temor e a esperança. Embora ambas as espécies de homens vivam no limite - o homem da imaginação que procura pela razão, e o homem da razão que não é capaz de livrar-se inteiramente da imaginação - ambos são instigados pelo temor $e$ amparados pela esperança. É incomparavelmente melhor, para eles, anelar pelo estado esperado dos acontecimentos do que fugir dos temidos. Pois, a esperança é um afeto de alegria que - ao contrário do de tristeza - pode muito bem ser ativo 
no sentido spinozista, quer dizer, pode ser baseado na idéia adequada do objeto intencional dele, enquanto a tristeza não pode, porém, ser passiva, basicamente, inadequada. Para ser claro, como dissemos, a esperança mesma nunca se tornará ativa. Ainda, ao contrário do temor, a esperança pode nos guiar para a atividade. Este aspecto da esperança encontramos reafirmados em alguns argumentos políticos do segundo magnum opus de Spinoza, o Tratado Teológico-Político. A questão é como as pessoas podem ser forçadas a observar as leis estabelecidas por um certo governo, dado que as duas principais forças motivadoras profundamente enraizadas na natureza humana são precisamente a esperança e o temor. De acordo com Spinoza, no cap.5 do Tratado Teológico-Político, a sociedade, na qual as leis são observadas por pessoas que esperam por recompensas, é preferível àquela na qual a maior parte das pessoas é motivadas pelo temor de punições.

Em segundo lugar, as leis de todo estado deviam ser tal modo dispostas, que homens são menos restringidos pelo temor do que pela esperança de algum bem, o qual eles desejam enormemente; isto assegurará que todos cumpram seu dever com entusiasmo (TTP, V).

Este tratado também dirige nossa atenção para um outro papel da esperança, o qual é estritamente relacionado ao caráter religioso possível desta emoção (Cf. Lagrée 7, p.91-103). ${ }^{2}$ No Prefácio, Spinoza reflete sobre as causas do porquê é tão difícil remover a superstição da mente dos homens. Ele nos induz a reconhecer a força motivacional da esperança.

A origem da superstição dada acima nos fornece uma clara razão para o fato, que acomete a todos os homens naturalmente, embora alguns atribuam sua origem a uma noção obscurecida de Deus, universal para o gênero humano, e que, também, tende a mostrar que ela não é menos inconsistente e variável do que outras alucinações mentais e impulsos emocionais, e, ademais, que não pode apenas ser mantida pela esperança, pelo rancor, pela raiva, e pela decepção; visto que surge, não a partir da razão, porém, unicamente a partir das mais poderosas fases da emoção. Além disso, precisamos entender prontamente o quanto é difícil manter no mesmo curso, homens predispostos a toda forma de credulidade. Pois, como a massa da humanidade se mantém aproximadamente sempre no mesmo nível de miséria, ela nunca admite, por muito tempo, um remédio, mas é sempre melhor satisfeita por uma novidade, que não tem ainda demonstrado ser ilusória.

Por conseguinte, a esperança tem um papel religioso eminente a representar em Spinoza, embora a citação se refira apenas a seu papel de sustentação da superstição, quer dizer, da falsa religião. Os objetos esperados das superstições são aqueles bens que são principalmente ilusórios: Há sempre alguns novos que ainda não demonstraram ser ilusórios, e por esta razão podem ser esperados, pelo menos até a ilusão evaporar. Para obter estes objetos, os homens são naturalmente predispostos a acreditar no poder superior de quaisquer daqueles que, como tais, são oferecidos.

Assim, podemos notar agora, como pode ser miserável o estado do homem da imaginação, abandonado à superstição. Pode-se imaginar, contudo, se este é o único papel da esperança como uma emoção religiosa em Spinoza. Considera ele que supersitione tollenda tollitur religio? ${ }^{3} \mathrm{~A}$ resposta imediata é: certamente não. Embora não apenas a falsa religião, mas também a verdadeira, possa ser "investida de tal pompa e cerimônia, que pode sair superior de todo choque, e ser sempre observada com reverência zelosa pela totalidade das pessoas", e embora o "nome precioso da religião" possa bem ser mal utilizado em regimes despóticos para fazer "homens [...] lutarem tão bravamente tanto pela escravidão como pela 
salvação, e contando para isto não a vergonha, mas a mais alta honra em arriscar seu sangue e suas vidas pela vanglória de uma tirano", tudo isto não altera o fato que Spinoza faz uso da "religião verdadeira" universal, a qual certamente não é idêntica à superstição, e não desaparecerá mesmo que a superstição seja apagada.

Mas existe um papel para a esperança na verdadeira religião spinozista? Certamente não esgotarei aqui a complexa questão da "verdadeira religião" em Spinoza. No entanto, certas demonstrações básicas precisam ser feitas em torno do tema da esperança. Evidentemente, a esperança por objetos ilusórios não pode ser tolerada na religião verdadeira. Ilusões sobre o uso real - ou o caráter nocivo dos objetos para nós -, são enraizadas nas idéias inadequadas da imaginação, das quais poderíamos inferir, para a conexão estreita da razão, idéias adequadas e religião verdadeira, mesmo que não encontrássemos as linhas seguintes na quarta parte de Ética:

De resto, remeto a religiosidade tudo quanto desejamos e fazemos e de que, enquanto temos a idéia de Deus, ou seja, enquanto conhecemos a Deus, somos a causa. Quanto ao desejo de fazer o bem, que surge por vivermos sob a condução da razão, chamo de civilidade. Já o desejo que leva o homem que vive sob a condução da razão a unir-se aos outros pela amizade chamo de lealdade. E chamo de leal aquilo que os homens que vivem sob a condução da razão louvam, e de desleal aquilo que contraria o vínculo da amizade. (Spinoza 10, IV, prop. 37, esc.1, p.307-309)

Se, de acordo com esta série de definições, os desejos verdadeiramente religiosos e as ações têm sua origem no modo racional de vida, tomados no estrito sentido spinozista, a esperança precisa ser esquecida para representar algum papel na verdadeira religião. Isto pode ser visto com abundante clareza no escólio da penúltima proposição da
Ética, parte 5, onde é dito que piedade e religião pertencem à "Firmeza do Ânimo" (Animi Fortitudinem) ${ }^{4}$ introduzida na parte 3, escólio da Proposição 59.5

Esta identificação não apenas mostra, novamente, as conexões essenciais entre moralidade e religião no século 17 , mas, também, que a maneira da verdadeira religião e a maneira de ser guiado pela razão são também dois lados da mesma moeda. Neste escólio, a esperança $-e o$ medo - são as principais emoções motivadoras daquelas pessoas que permanecem supersticiosas no sentido spinozista, quer dizer, que acreditam em uma vida pós-morte de recompensas e punições, em vez de conhecer, como o sábio, a natureza verdadeira e os ditados da razão, tanto quanto o caráter verdadeiro da eternidade da mente - que não tem nada que fazer na vida pós-morte.

Até então, tudo bem. Infelizmente, podemos estar bem certos que pessoas reais dificilmente chegariam algum dia ao estado da pura razão, sem mencionar o intelecto retificado do sábio spinozista, no qual não apenas nada mais há a temer, como também nada a esperar. Por isto, não penso que traímos o sentido spinozista, quando concluímos que a esperança, ao mesmo tempo como emoção do homem com uma doença letal e como motivação das pessoas governadas por legisladores prudentes, tem realmente - ao contrário do temor - um papel importante, que pode perfeitamente ser interpretado como papel moral-religioso, desde que sirva à conversão da superstição na verdadeira religião - pelo menos no sentido spinozista. 


\section{Amor}

A estrutura do amor, que oportunamente esbocei, pode certamente ser considerada, em geral, como paradigmática para os afetos mais básicos de Spinoza. Assim, há uma profusão de coisas que podem ser inferidas também no que concerne ao amor spinozista - sem qualquer pretensão de ser absolutamente exaustivo.

Gostaria de começar pelo final, quer dizer, pelo final da parte 5 da Ética. As passagens enigmáticas sobre o amor intelectual por Deus emergem de modo geral um tanto inesperadamente, mas há, além disso, alguns tópicos particulares que brotam de forma surpreendente e inesperada em meio ao conjunto. O tópico particular, que gostaria de acrescentar agora, é o tópico que tem um papel importante no tratamento cartesiano da espécie de amor que Descartes denomina "devoção": o temor da morte. Para Descartes, a melhor medicina contra o temor da morte é a devoção, que é principalmente amor por Deus ou amor pelo soberano. Esta, que é a cura cartesiana do temor da morte, é a pedra angular do princípio fundamental para uma - para ser exato, ela mesma, não desenvolvida em Descartes - teologia política. Contrariamente a isto, embora a terapia de Spinoza contra o temor da morte seja baseada em uma espécie de amor por Deus, este, posteriormente, não é politicamente motivado, mas pertence a uma metafísica do conhecimento.

Como os corpos humanos são capazes de muitas coisas, não há duvida de que podem ser de uma natureza tal que estejam referidos a mentes que tenham um grande conhecimento de si mesmas e de Deus, e cuja maior parte, ou seja, cuja a parte principal, é eterna, e que, por isso, dificilmente temem a morte. (Spinoza 10, V, prp.39, esc., p.405 itálico nosso).
Do mesmo modo, se há passagens, também em Descartes, que conectam o amor por Deus ao conhecimento de certas verdades, a base teológico-política é inegável e muito mais acentuada em seus escritos do que na Ética de Spinoza. Ao mesmo tempo, temos, também, uma passagem em Spinoza, na qual ele conecta a teologia política ao amor de Deus. Nas já citadas passagens do "Prefácio" ao Tratado Teológico-Político, ele encontra ocasião de falar no "precioso nome da religião", que pode ser mal usado por regimes despóticos para fazer os homens lutarem pela servidão como se lutassem pela liberdade e arriscarem-se pela glória de um tirano. Entretanto, para Spinoza, a contraparte de uma religião supersticiosa, explorada politicamente em favor de um tirano, não é, de nenhum modo, o uso político da religião verdadeira em favor de Deus como de um príncipe, isto é, o uso teológico-político do amor não era para ele uma opção viável - o que certamente não significa que o amor patriótico não possa estar de acordo com um papel político e religioso não contaminado. Susan James demonstrou recentemente que de acordo com a visão admitida em seu Tratado Teológico-Político, Spinoza foi um daqueles pensadores políticos da modernidade nascente que optaram pelo amor no lugar do temor quando a questão despontou, dos quais ele é o mais apto para representar a coerência de membros de um estado particular tão estável quanto possível. Ao contrário, os pensadores patriarcais não constroem sociedades políticas como unidades coerentes, ligadas pela mesma emoção da espécie de amor natural, que encontramos unindo membros de famílias naturais. Porém, ele contou com os efeitos benevolentes de uma espécie de amor artificial despertada pela realização de similaridades, semelhanças "em alguns aspectos importantes", como "dever cívico ou ocupação" compartilhada por aqueles que vêm de uma mesma cidade, são "unidos por uma vocação particular", ou são "estudantes e professores, ou adeptos de uma única religião" (James 6, p.43-54). Podemos nos referir a uma interessante 
cadeia de proposições na parte 3 da Ética, no qual Spinoza estabelece uma conexão entre as idéias de similitude, amor e classe social ou nação. Comecemos com a proposição 27 :

Por imaginarmos que uma coisa semelhante a nós e que não nos provocou nenhum afeto é afetada de algum afeto, seremos, em razão dessa imaginação, afetados de um afeto semelhante. (Spinoza 10, p.195)

Isto quer dizer, pura similaridade - "em alguns aspectos importantes" - basta deixar o "mecanismo", função que atualmente os biólogos denominam "contágio emocional”. E, embora Spinoza não diga isto explicitamente, somos autorizados a pensar, de acordo com ele, que ao ter realizado alguma similaridade significativa, estamos aptos para sentir o tipo de amor artificial necessário ao estabelecimento da "consciência de classe". E este amor pode certamente multiplicar a força do "contágio emocional". A proposição 21 diz:

Quem imagina que aquilo que ama é afetado de alegria ou de tristeza será igualmente afetado de alegria ou de tristeza; e um ou o outro desses afetos será maior ou menor no amante à medida que, respectivamente, for maior ou menor na coisa amada.

A Proposição 22 diz essencialmente o mesmo, segundo um outro ângulo:

Se imaginamos que alguém afeta de alegria a coisa que amamos, seremos afetados de amor para com ele. (Spinoza 10, p.189)

O primeiro corolário da proposição 27 nos mostra claramente o quanto o amor emerge daquela "imitação dos afetos". Spinoza a descreve aqui:

Se imaginarmos que alguém, que não nos provocou qualquer afeto, afeta de Alegria uma coisa semelhante a nós, seremos afetados de amor para com ele. (Spinoza 10, p.195)

Não apenas o amor realmente multiplica a eficácia do contágio emocional, mas um dos aspectos essenciais é seu empenho para ser multiplicado, como a proposição 33 nos lembra:

Quando amamos uma coisa semelhante a nós, esforçamonos, tanto quanto podemos, por fazer com que, de sua parte, ela nos ame. (Spinoza 10, p.203)

Note que Spinoza é perfeitamente ciente do fato embaraçoso que o ódio, em um grupo particular de pessoas, contra um outro grupo, pode acentuar consideravelmente a coesão entre os membros de ambos os grupos. A segunda sentença da proposição 22, e seu primeiro corolário citado acima, não nos deixa dúvida sobre isto:

Se, contrariamente, imaginamos que a afeta de tristeza, seremos, contrariamente, afetados de ódio contra ele. (Spinoza 10, p.189)

Assim, talvez, possamos concluir que o amor - um afeto de alegria - é capaz de unir pessoas internamente, enquanto que o ódio - um afeto de tristeza - é capaz de criar coesão grupal de uma maneira exterior. O que Spinoza diz na proposição 46 pode provavelmente ser interpretado ao longo dessas linhas:

Se alguém foi afetado, de alegria ou de tristeza, por um outro, 
cujo grupo nacional ou social é diferente do seu, alegria ou tristeza que vem acompanhada, como causa, da idéia desse outro, associada a designação genérica desse grupo, ele não apenas amará ou odiará esse outro, mas também todos os que pertencem ao mesmo grupo.(Spinoza 10, p.217)

Spinoza não dá exemplos de como o amor comum pode unir nações, enquanto faz menção de exemplos da força coesiva do ódio comum ${ }^{7}$.

Porém, ao retornar ao conceito de amor da Ética, a principal definição do amor, o primeiro afeto depois dos afetos básicos do desejo, da alegria e da tristeza, um afeto que possibilita passividade e atividade a ambos, é a seguinte:

6. O Amor é uma Alegria acompanhada pela idéia de uma causa externa.

Explicação: Esta definição explica muito claramente a essência do amor. Já a definição dada pelos autores que definem o amor como a vontade do amante de unir-se à coisa amada não exprime a sua essência, mas uma de suas propriedades. E como a essência do amor não foi suficientemente examinada por esses autores, tampouco puderam ter qualquer conceito claro dessa propriedade, o que fez com que todos julgassem sua definição extremamente obscura. (Spinoza 10, p.241-2)

Existe um grande número de questões em aberto concernentes a esta definição, e, também, à maneira como Spinoza faz uso dela. Não é claro o que significa "acompanhamento"; não é claro porque Spinoza fala de uma causa "externa", dado que a fonte da alegria, ao produzir amor ativo, é a transição para um aperfeiçoamento maior de nossa própria alma cognoscente (Cf. Martins 8)
Talvez a principal dificuldade que motiva os comentadores a exercitar sua clareza interpretativa é o caráter interno da alegria, essencial para o amor, que é, porém, uma transição para uma maior perfeição, e não a posse completa da mais alta de todas as perfeições. Certamente, este é um aspecto que ameaça o mais emblemático conceito de Spinoza, o amor intelectual por Deus. Sem ser capaz de estender-me muito nestes problemas, gostaria de sugerir uma provável solução. Por que não considerar o amor por Deus no sentido de estado de satisfação, de posse da mais elevada alegria como um conceito incerto? Não há ninguém que tenha a posse de um completo amor intelectual por Deus; construímos este conceito a fim de entender e encorajar continuamente nosso procedimento no caminho para o estado absolutamente "raro", "excelente", "difícil", e, ainda, "rigoroso" da "bem-aventurança". 8

Por mais que a interpretação do conceito de amor de Spinoza seja laboriosa, se retornarmos à definição do amor encontrada acima, uma coisa torna-se profusamente evidente: aquele que ele critica por seu conceito obscuro do papel da vontade no amor é Descartes. Ele mesmo pensa as leis que regulam a incitação dos afetos, apresentados na parte 3 da Ética, como sendo leis geométricas, as quais ele promete dar seqüência no Prefácio deste mesmo livro 3. A vontade é, no melhor dos casos, um conceito da psicologia popular que não tem valor explanatório em um tratado filosófico mais geométrico.

Com o fim de acentuar a significação e o suporte científico contemporâneos para naturalizar a ordem moral de Spinoza, permito-me aludir ao trabalho do biólogo holandês Frans B. M. De Waal (De Waal 11). A principal preocupação de De Waal é que sua disciplina, a biologia evolucionária, quando se dedica à questão dos valores morais, parece virar-se para a direção errada ao destacar a esfera inteira da ordem moral a partir da evolução natural. De acordo com De Waal, isto contraria ambos, a 
compreensão original de Darwin e os fatos descobertos por - em parte sua própria-investigação em torno do comportamento dos primatas. Para dispor isto de uma maneira menos abstrata, a questão de De Waal é que os biólogos de proa seguem Thomas Henry Huxley ao duvidarem que a evolução possa conduzir aos valores morais, endossando a visão de que toda moralidade é criada pela cultura contra a evolução natural e o geneticamente baseado egoísmo instintivo de nosso ser puramente biológico. Contrariamente a isto, De Waal argumenta em favor da visão naturalista segundo a qual o próprio Darwin, em A Origem do Homem (1871) "inequivocamente acentuou a moralidade como parte da natureza humana."(De Waal 11, p.7). Darwin reconheceu que a promoção do comportamento de servir-se a si mesmo "de nenhuma maneira impede a evolução do altruísmo e das tendências simpáticas" e "enfatizou a continuidade com os animais até mesmo no domínio moral" (Idem, p.11). De fato, não é necessário acentuar que esta ênfase na simpatia da visão de Darwin deve sua origem a David Hume e a Adam Smith, e, neste sentido, alguém poderia argumentar que Darwin foi mais inspirado por sua predileção filosófica a priori do que por experimentos a posteriori. Porém, o interessante é que, não obstante Darwin poder ter sido profundamente influenciado pela filosofia escocesa, as buscas experimentais contemporâneas parecem também sustentar suas teses. De Waal usa a expressão "contágio emocional” para referir-se ao que acontece em crianças de um ano, em animais domésticos e em primatas que habitam a selva, "o estado emocional de um indivíduo induz a um estado de emparelhamento e de afinidade em outro" (Idem, p.16). Isto ele considera como o primeiro estrato de seu "Modelo do Boneco Russo", que é significativo para mostrar como as formas de empatia, embasadas socialmente na cognição consciente e na cultura, se desenvolvem, não contra "esta base bem amarrada, firme" do "impacto emocional automático", mas para além dela (Idem, p.23). Tudo isto parece levar a concluir que a investigação das condições básicas de nossa vida, de valor neutro em si mesma, encontrou o valor primitivo da importância de outros na forma do fenômeno do contágio emocional. E ainda se é verdade que uma espécie de teleologia parece estar envolvida no quadro, isto não nos coloca atrás no campo da evolução natural:

Visto que a sobrevivência de muitos animais depende da ação concertada, da ajuda mútua, e da transferência de informação, a seleção deve ter favorecido mecanismos imediatos para avaliar os estados emocionais de outros e rapidamente responder a eles sob formas adaptativas. (De Waal 11, p.17)

Não é difícil descobrir que o argumento de De Waal é digno de todo respeito, paralelamente ao que propriamente aderimos da Ética. $\mathrm{Na}$ Proposição 27 da parte 3 da Ética citada acima, Spinoza antecipa claramente a idéia de De Waal, Hatfield et al. (cf. Hatfield 5, p.96-99). Permitam-me citar agora a demonstração desta proposição que certamente lança luz sobre as diferenças de método entre um filósofo seguindo a ordem geométrica do século 17 e um cientista atual. Spinoza alega:

As imagens das coisas são afecções do Corpo humano, cujas idéias representam corpos exteriores como presentes a nós, isto é, cujas idéias envolvem a natureza de nosso corpo e, ao mesmo tempo, a natureza presente de um corpo exterior. Assim, se a natureza de um corpo exterior é semelhante à de nosso corpo, então a idéia do corpo exterior que imaginamos envolverá uma afecção de nosso corpo semelhante à do corpo exterior. Conseqüentemente, se imaginarmos que alguém semelhante a nós é afetado com algum afeto, essa imaginação exprimirá uma afecção de nosso corpo semelhante àquele afeto. Portanto, por imaginarmos que uma coisa semelhante a nós é afetada de algum afeto, seremos afetados de um afeto 
semelhante ao seu. Mas, se odiarmos uma coisa semelhante a nós, então, seremos afetados, neste caso, não de um afeto semelhante ao seu, mas de um afeto contrário. (Spinoza 10, III, prop. 27, dem., p.195)

Por mais diferentes que seus respectivos métodos possam ser, podemos também ter uma perfeita compreensão do sentido spinozista do Modelo do Boneco Russo de De Waal. Pelo fato de a imitação dos afetos, caracterizados acima, não envolver um mínimo de atividade cognitiva, esta imitação pode ser tomada para estabelecer o nível mais básico de empatia. O nível seguinte é alcançado nas proposições 21 a 24, quando Spinoza fala sobre a transferência dos afetos no caso em que já se está "ajustado" emocionalmente: amamos ou odiamos a coisa em questão.

Quem imagina que aquilo que ama é afetado de alegria ou de tristeza será igualmente afetado de alegria ou de tristeza; e um ou outro desses afetos será maior ou menor no amante a medida que, respectivamente, for maior ou menor na coisa amada. (Spinoza 10, III, Prop.21, p.189).

Entretanto, se lembrarmos que Spinoza também menciona o caso simétrico quando uma pessoa odeia outra e, assim, por implicação, ela encontra alegria em sua mágoa, isto poderia sugerir uma contradição ao Modelo do Boneco Russo: o segundo nível não parece conter o primeiro. Porém, Spinoza acrescenta uma importante nota à proposição 23, ao lembrar ao leitor que "Esta alegria dificilmente pode ser duradoura e sem qualquer conflito mental. À medida que (como devo demonstrar imediatamente na prop. 27) alguém imagine que algo, como ele mesmo, é afetado com um afeto de tristeza, ele estará triste. E o oposto, se alguém imagina que a mesma coisa é afetada com a Alegria" (Spinoza 10, p.191). E, assim, ele deixa mais do que claro que assume a existência de uma relação de implicação à maneira do Boneco Russo.

Depois do segundo nível, ao qual alguém pode também ser ajustado através de idéias inadequadas, o que segue é o terceiro nível, onde não existe mais espaço para o rancor. Ainda, se estamos magoados por alguma ofensa, o ódio que resulta disto é "para ser conquistado pelo amor, ou pela generosidade, não por retribuir isto com ódio em retorno.” (Spinoza 10, V, prop.10, esc., p.379). Este princípio de uma empatia natural tripla poderia ser estendido a várias formas de sociedades humanas, porém, não é minha tarefa adentrar agora por esta direção. A moral, que eu gostaria de extrair da comparação com De Waal, é que Spinoza elaborou uma idéia de uma teologia sem um mantenedor e um criador transcendental de um telos, a qual parece fechada para o que, hoje, ambos, neurocientistas e biólogos, denominam ou praticam de uma forma nova.

\section{Generosidade}

Ao mostrar de uma maneira bem rápida, como o terceiro nível de empatia amorosa, sem qualquer traço de rancor, completa o Modelo do Boneco Russo em Spinoza, preparamos já a maneira de tratar, neste artigo, da terceira emoção, que é a generosidade.

Permitam-me lembrar, de modo bem breve, o que penso serem as principais características da generosidade cartesiana, que Spinoza deve ter conhecido muito bem ao desenvolver seu próprio conceito.

Por ora, a generosidade cartesiana é um expediente para superar as deficiências éticas do conceito metafisicamente funcional de um eu penso, ego cogitans, o qual poderia, de outro modo, nos induzir ao desenvolvimento de um universo solipsista. $\mathrm{O}$ universo cartesiano é guiado 
por um Deus pessoal; a maneira indireta como ele governa os eventos mundanos dá-se através do amor e pelo esforço em direção à perfeição distribuída a todas as criaturas. A generosidade é uma paixão do homem e, ao mesmo tempo, sua virtude, a qual consiste no reconhecimento da liberdade dada por Deus e da benevolência da vontade em nós e - lógica e simultaneamente - nos outros, guiando-nos à descoberta da comunidade original do gênero humano.

É apenas no fim da terceira parte da Ética, no escólio da proposição 59, que os afetos, que não são originados da imaginação, que são aqueles não passivos, paixões no sentido técnico do termo, são mencionados.

Remeto todas as ações que se seguem dos afetos que estão relacionados à mente a medida que ela compreende, à fortaleza, que divido em firmeza [fortitudo] e generosidade [generositas]. Por firmeza compreendo o desejo pelo qual cada um se esforça por conservar seu ser. Por generosidade, por sua vez,compreendo o desejo pelo qual cada um se esforça, pelo exclusivo ditame da razão, por ajudar os outros homens e para unir-se a ele pela amizade. (Spinoza 10, p.235)

O que é mais conspícuo na conexão com esta definição é que, enquanto a inter-individualidade, contida no conceito de Descartes da generosidade, tem que ser desenterrada através de uma análise de seu conceito de favor, a mesma inter-individualidade é caracterizada, no tratamento da generosidade em Spinoza, a partir do verdadeiro princípio.

Como sabemos, Spinoza desenvolve sua teoria dos afetos de modo mais sistemático do que Descartes. Ele tem, porém, três afetos primários, desejo, alegria e tristeza. Não obstante no escólio da proposição 59 da terceira parte temos apenas desejo e alegria, não podendo ocorrer, pois, que um afeto ativo tenha origem na tristeza. A generosidade spinozista é conectada primeiro ao desejo e, em segundo lugar, à amizade, e é precisamente, isto o que constitui sua diferença própria e específica dentro de seu genus proximum, o qual é fortitudo, força de ânimo. Posto que Spinoza assevera, sem ambigüidade, que estas ações, que ele reconhece como generosas, não aspiram somente a algo que é apenas vantajoso para o agente mesmo. Para ele, o respeito pelas necessidades dos outros é constitutivo de qualquer ação generosa.

Eu acredito que é uma característica distintiva adicional à teoria spinozista da generosidade, que a perspectiva de outros seja introduzida sob o título da "amizade" (amicitia). Como uma questão de fato, Descartes havia já estabelecido ligações sistemáticas entre os conceitos etimologicamente vinculados de amor e de amizade. Gostaria de propor que se interpretasse o conceito de Spinoza de amizade (amicitia) como paralelo ao de amizade em Descartes, quer dizer, como o tipo de amor onde o amante e o objeto amado, ao compor o conjunto da relação de amor, são de igual valor. Colocando à parte esta semelhança, entretanto, é muito mais importante reconhecer a diferença crucial entre os dois tratamentos do amor e da amizade. É a amizade, unicamente, que Spinoza assume entre os três tipos cartesianos de amor: afeição, amizade e devoção. A significação deste movimento é que, logo de início, um relacionamento desigual entre seres humanos está excluído do vocabulário de Spinoza concernente tanto ao amor como ao pensamento sobre ele em geral.

A Generosidade é, assim, um afeto altamente positivo, que é originado do desejo e do amor, com a amizade como uma mediadora. "oAmor é" - para lembrar a já citada definição - "uma alegria acompanhada pela idéia de uma causa externa". Deixem-me elaborar, além da já mencionada característica da filosofia de Spinoza, que consiste em refutar em tomar seriamente a vontade como um conceito filosófico: "Já a definição dada pelos autores que definem o amor como a vontade do amante de unir-se à 
coisa amada não exprime a sua essência, mas uma de suas propriedades".

Não deveria nos surpreender como Spinoza prescinde completamente da vontade em sua filosofia: não apenas da boa vontade, dirigida para o Bem pela providência divina, porém, também, e mais basicamente, da idéia de nossa autonomia para dispor indiferentemente nossas volições. "Deus ou Natureza" - esta é uma expressão frequentemente fundada em ambos, nas Paixões da Alma de Descartes e na Ética de Spinoza. Porém, enquanto em Descartes ela designa uma natureza impregnada pelo divino, cuja base transcendente permanece a uma distância do universo criado, em Spinoza, ela revela um deus naturalizado, quer dizer, um deus que não age à maneira da decisão livre indiferente a sua vontade.

Em Spinoza, o fato de não existir boa vontade tanto no nível humano como no divino, não implica que pessoas generosas não possam ser amigáveis com relação às outras, no sentido pleno da palavra, ainda que esta amizade não tenha fundação na faculdade inata da vontade livre, como em Descartes. As últimas proposições da quarta parte da Ética sobre o homem livre, explicam claramente que a liberdade não tem de ser necessariamente fundada na autonomia para dispor indiferentemente nossas volições para sermos eficientes na vida. Na proposição 71 , encontramos todos os ingredientes de uma teoria da generosidade, sem vontade boa e livre, ainda que Spinoza não empregue o termo "generositas" para este afeto do homem livre.

Proposição 71: Só os homens livres são muito gratos uns para com os outros.

Demonstração: Só os homens livres são muito úteis uns para com os outros e se unem entre si pelo mais estreito laço de amizade[máxima amicitiae necessitudine], e se esforçam com a mesma intensidade de amor por fazerem bem uns aos outros[parique amoris studio]. Por isso, só os homens livres são muito gratos uns para com os outros. (Spinoza 10, p.347)
Não é, também, difícil de reconhecer a reciprocidade e a igualdade no relacionamento dos homens livres, que caracterizam o amor na forma da amizade para ambos, Spinoza e Descartes. Spinoza refere-se ao primeiro corolário à proposição 35 da quarta parte, na qual é colocado que viver sob a direção da razão faz as pessoas viverem harmoniosamente, quer dizer, as torna mais benéficas para outras. Consequentemente, a generosidade spinozista não depende de um deus dotado de boa vontade, que criou o homem com uma boa vontade similar a sua própria, e que estabeleceu, ao mesmo tempo, um domínio no meio do universo, onde é possível agir de acordo com as decisões livres desta boa vontade. Além disso, ainda que não possa ser negado que a linha básica do argumento na Ética, que concerne à faculdade de harmonizar o comportamento das pessoas, seja intelectualista, entre homens que não vivem sob a direção da razão, uma espécie de "proto-generosidade" pode também ser detectada. Como vimos, quando tratamos das análises do "contágio emocional", Spinoza acredita que a semelhança é suficiente para incitar em nós uma emoção similar àquela de um outro, se somos neutros para com o outro. Em vez de me deter mais tempo sobre a semelhança elementar, citarei as palavras de Spinoza que concernem ao papel que a generosidade deve representar em nossa vida, quando não somos (ainda) sábios - o qual é também o período da geração da emoção de base instintiva. Parece-me que o argumento seguinte é o foco onde todos os ingredientes da teoria de Spinoza estão reunidos. A passagem que tenho em mente é o escólio da proposição $10 \mathrm{da}$ Parte 5 da Ética, onde nos é proposto um método baseado na imaginação para dele fazermos uso neste período da vida - o qual é, para muitos de nós, o único. A principal idéia é a seguinte. Primeiro, formamos princípios de vida sustentados pelo segundo tipo de cognição. Segundo, os gravamos em nossa memória, e, terceiro, os aplicamos aos casos particulares da vida real. 
Como resultado deste procedimento, nossa imaginação será informada de uma maneira especial, e, até mesmo, nos casos em que não somos capazes de deixar a razão regular nossa vida diretamente e continuamente, nossa imaginação nos governará de acordo com as pré-impressas linhas-guias da razão. Quais são as “máximas de vida” que Spinoza recomenda?

Por exemplo, estabelecemos, entre as regras de vida, que o ódio deve ser combatido com o amor ou com a generosidade, em vez de ser retribuído com um ódio recíproco. Entretanto, para que esse preceito da razão esteja sempre à nossa disposição quando dele precisamos, deve-se pensar e refletir sobre as ofensas costumeiras dos homens, bem como sobre a maneira e a via pelas quais elas podem ser mais efetivamente rebatidas por meio da generosidade. Ligaremos, assim, a imagem da ofensa à imaginação dessa regra, e ela estará sempre à nossa disposição quando nos infligirem uma tal ofensa. Pois, se também tivermos à disposição o princípio de nossa verdadeira utilidade, assim como a do bem que se segue da amizade mútua e da sociedade comum; e se considerarmos, além disso, que a suprema satisfação do ânimo provém do princípio correto de viver; e que os homens agem, como as outras coisas, em virtude da necessidade da natureza; então a ofensa - ou seja, o ódio que costuma dela provir - ocupará uma parte mínima da imaginação e será facilmente superada. (Spinoza 10, V, prop.10, p.379-381)

Como é notório, esta regra já foi introduzida na proposição 46 da parte 4 .

Quem vive sob a condução da razão se esforça, tanto quanto pode, por retribuir com amor ou generosidade, o ódio, a ira, o desprezo, etc. de um outro para com ele. (Spinoza 10, p.321)
O propósito de Spinoza é surpreendente: não é o reconhecimento da liberdade e, essencialmente, da boa vontade em nós e em outros, que nos induz a ser generosos, porém, o contrário: o reconhecimento do fato "que homens, como outras coisas, agem a partir da necessidade da natureza." Podemos ainda acrescentar que se Descartes foi autorizado a interpretar o homem como a imagem de Deus, seu criador, na base da integridade e da autonomia da vontade presente em ambos, Spinoza poderia pensar que o agir a partir da necessidade da natureza é uma "imagem" da maneira determinadamente livre como a natura naturans "age". Descartes escreve a Elizabete, em 15 de setembro de 1645, o seguinte: "quando elevamos nossa mente para considerar [o verdadeiro objeto do amor, que é a perfeição], encontramos a nós mesmos naturalmente tão inclinados para amá-lo que recebemos alegria até de nossas aflições, quando pensamos que sua vontade se realiza pelo o que sofremos." "O que Descartes tinha em mente era o Deus transcendente, dotado de uma vontade livre. Em contraste com isto, apesar de Spinoza estar um tanto convencido que nos sentimos naturalmente inclinados para amar Deus, como Descartes, a motivação para esta inclinação foi naturalizada: é precisamente a secreta necessidade de tudo o que acontece. Se Descartes recebia alegria até mesmo de suas aflições físicas, isto foi suficiente para o persuadir de que era a metafísica inteira, a moral e a religião, determinada pela vontade divina, que se realizava nelas, destituidas de vontade livre no que tange às causas físicas. E se ele recebia alegria de suas aflições morais, isto foi suficiente para convencê-lo de que a causa humana das aflições tomava posse de sua própria vontade livre, empregada pela vontade divina para se realizar. Contrariamente a isto, Spinoza não estava inclinado a admitir um ser de vontade divina, como um ator secreto por trás dos seres físicos e morais, justificando nossas aflições, físicas ou morais.

Chegamos ao ponto, no qual podemos concluir nossa discussão 
sobre Spinoza. A generosidade spinozista é estreitamente conectada ao amor e à amizade, porém, esta conexão não foi estabelecida por um Deus pessoal e, também, amoroso. O amor de Deus em Spinoza não pode, porém, ser interpretado a partir da perspectiva do amor humano, como uma espécie de conceito limítrofe que enriquece o amor e encoraja o amante mesmo, ao conduzi-lo cada vez mais próximo ao aspecto dinâmico, eficiente da natureza.

\section{Secularização}

Após fazer esta avaliação dos afetos escolhidos como casos paradigmáticos dos afetos religiosos antigos e sempre possíveis, podemos nos perguntar o que falta nas análises sublinhadas acima da esperança e do temor, do amor, da generosidade, e o que substituiu o impulso religioso.

Em consideração à transparência, citarei algumas passagens de Tomás de Aquino, não por pretender uma ambiciosa comparação histórica, porém, para ser capaz de ver mais claramente a fenda que foi aberta no período da "dissolução da perspectiva medieval". Não aspirarei por completude: confinarei minha comparação à emoção da esperança.

Permitam-me apenas que me refira a quarta parte das Questões Discutidas sobre as Virtudes de Aquino, a qual trata da Esperança. No “artigo 1: se a esperança é uma virtude”, nas objeções 5 e 6, emerge a questão que distingue a esperança e o amor, como emoções que "dão seus nomes às virtudes", de outros afetos como a saudade e o prazer, que não o fazem. Ao responder, Aquino deixa claro que apenas as virtudes teológicas podem extrair seus nomes diretamente de "movimentos, ou emoções" da mente. A Esperança, enquanto uma emoção, pode apenas ser eminente por dar nome a uma virtude teológica, quando seu objeto não for ruim, quer dizer, for o objeto duplo da "vida eterna mesma" por um lado, e "a ajuda de Deus, através da qual podemos esperar alcançá-la.” (Aquinas 1, p.221).

Em Spinoza, podemos também ter um tipo de esperança eminente, como vimos. Porém, esta esperança, certamente, não pode ser considerada uma virtude isolada de uma virtude teológica. Podemos esperar "objetos ruins", quer dizer, bens ilusórios, enquanto o objeto da esperança eminente é o mais alto bem real, o qual é o conhecimento amoroso da união da mente com a natureza inteira. Se existe um segundo objeto desta esperança, este não é, certamente, a ajuda da Natureza-Deus no nível da substância. Apenas causas finitas, "homens livres" guiados pela razão, podem nos ajudar, em primeiro lugar, a obter este estado, o qual pode ser chamado eternidade da mente, como vimos. Porém, não no sentido de uma pós-vida, onde devemos experimentar o prazer 'como uma das dádivas da bemaventurança"(Aquinas 1, p.223).

Existe também um aspecto político de distinção da esperança em Spinoza: em um Estado bem-governado as pessoas observam as leis do Estado com base na esperança por recompensa como uma espécie de alegria, a qual pode nos guiar ao Estado de um homem livre que segue as leis como se fossem sua sponte ${ }^{10}$, ao ter o prazer necessário sem qualquer esperança ou necessidade de que lhe sejam dadas recompensas.

\section{REFERÊNCIAS BIBLIOGRÁFICAS}

1. AQUINAS, T. Disputed Questions on the Virtues. Ed. E. M. Atkins \& Th. Williams Cambridge: CUP, 2005

2. AVERILL, J. R. "Intellectual Emotions", in: Harré, R., Parrott, W. G. (eds): The Emotions. Social, Cultural and Biological Dimensions. London: Thousand Oaks, 1996. 
3. BOROS, G. "Love as a Guiding Principle of Descartes's Late Philosophy" in: History of Philosophy Quarterly, 20 (April 2003) 149-163

4. BLUMENBERG. The Legitimacy of the Modern Age. Cambridge: MIT, 1983

5. HATFIELD. E., CACIOPPO, J.T .and. RAPSON, R. L: “Emotional Contagion”, in: Current Directions in Psychological Science 2.

6. JAMES, S. "The role of Amicitia in Political Life", in: G. Boros, H. de Dijn \& M. Moors (eds): The Concept of Love in Seventeenth-and Eighteenth-Century Philosophy. Budapest / Leuven: Eötvös Kiadó / Leuven University Press, 2007

7. LAGRÉE, J. "Les passions religieuses chez Spinoza" in F. Brugère \& P.-F. Moreau (eds): Spinoza et les afects. Paris: Sorbonne, 1998

8. MARTINS, A. "L'amour : cause et concomitance" in Jaquet, C.; Sévérac, P.; Suhamy, A. (eds). Spinoza philosophe de l'amour. Saint-Étienne: P.U. Sant-Étienne, 2006

9. MATHERON, A. "O problema da evolução de Spinoza do Tratado teológicopolítico ao Tratado político" in E. M. Curley; P.-F. Moureau (eds): Spinoza Issues and Directions: the Proceedings of the Chicago Spinoza Conference. Leiden: Brill, 1990.

10. SPINOZA, B. Ética. Edição bilíngüe latim/português, Tradução e notas: Tomaz Tadeu. Belo Horizonte: Autêntica, 2007

11. DE WAAL, F. B. M. "Morality and the Social Instincts: Continuity with the Other Primates", in Grethe B Peterson (ed.) The Tanner Lectures on Human Values, 25. Salt Lake City: The University of Utah Press, 2005, p.1-40.

\section{The secularization of the religious affects in Spinoza's works: hope and fear, love} and generosity

Abstract: Positioning himself as «natural philosopher» in the treatment of the passions, Descartes initiates a secularization of affects or emotions. Surely with regard to this he is followed by Spinoza. In both cases, the philosophical approach of affection is to release them from a moral perspective, secularizing in this manner the emotions: separated from morality, their explanations are no more attached to religion, since the moral is based on the idea of transcendent God. At this point, Spinoza goes further than Descartes at the secularization of emotions, because in Spinoza God is naturalized, God sive natura. Generosity, for example, does not depend on a God endowed with good will, but on the natural exercise of human reasoning as part of the rationalized Nature. So that even the intellectual love of God would not be a substitute for religious moral impulse: to Spinoza, this love, as well as generosity and friendship, is in necessary order of nature, neither depending on a divine free will, nor being reducible to human will exclusively.

Keywords: emotion, morality, secularism, love, generosity

\section{NOTAS:}

1. O século 17 é o período em que figura proeminentemente nas teorias ou a manutenção ou a crítica da tese que o principal traço da prematura modernidade é ser construída como a secularização dos genuínos bens religiosos ou teológicos. No que concerne a este debate sigo Blumenberg: a meu ver, aquilo que períodos mais tardios retomam do período imediatamente anterior, não são soluções substanciais, mas questões selecionadas sem respostas, tarefas sem soluções - entretanto, as respostas e soluções alegadas, elaboradas nos períodos precedentes, fizeram crescer o vazio de significado. É neste sentido, que minha investigação visa revelar algumas formas particulares de "secularização" das emoções religiosas tomadas nas teorias dos pensadores mencionados acima. Tomei esta expressão no sentido de compreender questões que vêm adquirindo alguma relevância na nova ordem do conhecimento, sem as respostas das quais elas eram providas na antiga ordem. Para esta interpretação de "secularização", ver Blumenberg: "O que ocorre, principalmente, no processo que é interpretado como secularização, pelo menos até agora em aproximadamente algumas instâncias reconhecíveis e específicas, deveria ser descrito não como a transposição do conteúdo autenticamente teológico na alienação secularizada desde sua origem, porém, mais propriamente, como a reocupação das posições de resposta que tornaramse vagas e às quais correspondem questões que não podem ser eliminadas". (Cf. Blumenberg 4).

2. Contudo, sua interpretação das emoções religiosas difere consideravelmente da que demonstro neste artigo

3. Ao suprimir a superstição, a religião é suprimida (N.T.)

4. "Parece ser outra a convicção comum do vulgo. Com efeito, são muitos os homens 
que parecem acreditar que são livres apenas à medida que lhes é permitido entregaremse à licenciosidade e que renunciam a seus direitos se são obrigados a viver conforme os preceitos da lei divina. Acreditam, assim, que a civilidade e a religiosidade e, em geral, tudo que está referido a fimeza do ânimo, são fardos de que eles esperam livrarse depois da morte, para, então, receber o preço da sua servidão, ou seja, da civilidade e da religiosidade. E não é apenas por essa esperança, mas também, e sobretudo, pelo medo de serem punidos, depois da morte, por cruéis suplícios, que eles são levados a viver, tanto quanto o permitem sua fraqueza e seu ânimo impotente, conforme os preceitos da lei divina. Se os homens não tivessem essa esperança e esse medo, e acreditassem, em vez disso, que as mentes morrem juntamente com o corpo, e que não está destinada, aos infelizes esgotados pelo fardo da civilidade uma outra vida, além desta, eles voltariam a sua maneira de viver, preferindo entregar-se a licenciosidade e obedecer ao acaso e não a si mesmos".

5. "Todas as ações que seguem dos afetos referidos à Mente enquanto intelige eu refiro à Fortaleza, que distingo em Firmeza e Generosidade. Pois por Firmeza entendo o Desejo pelo qual cada um se esforça para conservar seu ser pelo só ditame da razão. Por Generosidade entendo o Desejo pelo qual cada um se esforça para favorecer os outros homens e uni-los a si por amizade pelo só ditame da razão."

6. Quanto ao tratamento do amor por parte de Descartes ver Boros 3.

7. Talvez não seja inapropriado lembrar, neste ponto, que Alexandre Matheron desenvolveu uma reconstrução evolucionista do conceito spinozista da gênese de um estado, precisamente ao longo destas linhas, baseado no Tratado Político de Spinoza, contra aqueles que sustentam que Spinoza seja um filósofo contratualista. Podemos encontrar esta análise em Matheron 9, p. 258-270.

8. Note que a expressão "bem-aventurança" (beatitudo) atesta o encadeamento da moralidade e da (reinterpretada) religião, que equivale a prover ambos de um caráter "secularizado".

9. "quando elevamos nosso espírito para considerá-lo tal qual ele é [o verdadeiro objeto do amor, que é a perfeição], encontramos a nós mesmos naturalmente tão inclinados para amá-lo, que tiramos a alegria mesmo de nossas aflições, ao pensar que sua vontade se realiza nisto que as recebemos."

10. De seu próprio movimento ou vontade (N.T.).

\section{HERMENÊUTICA E PLURALISMO SUBJETIVO: O FUNDAMENTO DA LIBERDADE NO PENSAMENTO DE \\ ESPINOSA}

\section{Victor-Manuel Pineda Santoyo*}

Resumo: Este trabalho tem como propósito central expor uma das aspirações mais caras à filosofia de Espinosa: a liberação da faculdade de julgar, tanto como perspectiva hermenêutica como em seu significado político. A partir deste conceito, pretendese reconstruir alguns tramos do programa do filósofo, sempre enfático a respeito da liberdade, tanto no âmbito ético como no político, e os diversos significados que esta tem em sua obra. Há uma liberdade concebida sub specie aeternitatis e uma liberdade sub specie durationis? A questão leva a estabelecer a relação que este filósofo tem com as coisas do mundo político, sempre movido a partir de paixões e interesses e, frequentemente, afastado de um sentido virtuoso da liberdade. Sem abandonar as aspirações de um sentido superior da liberdade, o autor sustenta que Espinosa se propõe examinar o problema da liberdade em um contexto no qual há mais prejuízos que idéias adequadas, mais temores que esperanças, mais superstição que sabedoria. Palavras-chave: liberdade, hermenêutica bíblica, faculdade de julgar.

\section{A fonte das liberdades subjetivas}

Nas páginas mais notáveis do pensamento espinosano concorrem diversos graus e concepções da liberdade. Essas noções sempre foram vinculadas por Espinosa à diversidade de técnicas intelectuais que possui o entendimento para percepções das coisas: da mesma forma podiam ser referidas à constituição imaginária da subjetividade, isto é, ao erro e às ficções mais delirantes, como à potência que a alma possui para ser

* Professor de Filosofia na Univerdad Nicolaita - México.

Texto traduzido por Daniel Santos (Doutorando do Departamento de Filosofia da USP). 